\title{
SiteHopper - a unique tool for binding site comparison
}

\author{
Jose Batista ${ }^{1 *}$, Paul CD Hawkins², Robert Tolbert ${ }^{2}$, Matthew T Geballe ${ }^{2}$ \\ From 9th German Conference on Chemoinformatics \\ Fulda, Germany. 10-12 November 2013
}

Knowledge of and information about protein binding sites has become increasingly important in the drug discovery process and not just for molecular biologists [1]. By comparing binding sites within and across protein families, relevant details about the functionality and selectivity of a target protein can be extracted leading to useful insights for the development of new ligands [2]. SiteHopper provides a powerful alternative method to the traditional use of sequence alignment for this purpose. Using OpenEye's Shape [3] and Spicoli toolkits [4], SiteHopper quickly calculates a 3D shape representation of the active site colored by the chemical properties of the protein residues defining the active site. These active site representations can be rapidly aligned and assessed for shape and chemistry similarity. As SiteHopper is built on the OpenEye toolkits, it is highly flexible and customizable for a variety of end-uses. In this presentation, the methodology behind SiteHopper will be introduced and multiple relevant applications will be shown.
doi:10.1186/1758-2946-6-S1-P57

Cite this article as: Batista et al:: SiteHopper - a unique tool for binding site comparison. Journal of Cheminformatics 2014 6(Suppl 1):P57.
Authors' details

${ }^{1}$ OpenEye Scientific Software, Cologne, 50672, Germany. ${ }^{2}$ OpenEye Scientific Software, 9 Bisbee Court, Suite D, Santa Fe, NM, 87508, USA.

Published: 11 March 2014

\section{References}

1. Paquet $E$, Viktor $H$ : An exhaustive Shape-based approach for proteins' Secondary, Tertiary and Queaternary Structures Indexing, Retrieval and Docking. Prot Struct 2012, 121-132.

2. Binkowski T, Joachimiak A: Protein Functional Surfaces: Global Shape Matching and Local Spatial Alignments of Ligand Binding Sites. BMC Struct Biol 2008, 8.

3. Shape Toolkit 1.9.1: OpenEye Scientific Software, Santa Fe, NM. [http:// www.eyesopen.com].

4. Spicoli Toolkit 1.2.1: OpenEye Scientific Software, Santa Fe, NM. [http:// www.eyesopen.com].

* Correspondence: batista@eyesopen.com

'OpenEye Scientific Software, Cologne, 50672, Germany

Full list of author information is available at the end of the article

\section{Publish with ChemistryCentral and every scientist can read your work free of charge \\ "Open access provides opportunities to our colleagues in other parts of the globe, by allowing anyone to view the content free of charge." \\ W. Jeffery Hurst, The Hershey Company. \\ - available free of charge to the entire scientific community \\ - peer reviewed and published immediately upon acceptance \\ - cited in PubMed and archived on PubMed Central \\ - yours - you keep the copyright \\ Submit your manuscript here: \\ http://www.chemistrycentral.com/manuscript/

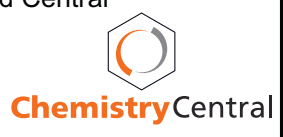

